\title{
Reaching out - GUM in the General Practice setting
}

\author{
J Watt, T Streeter, C Battersby, S Ashton, S Herbert \\ Ashwood Centre, Northamptonshire Integrated Sexual Health, Kettering
}

\section{Introduction}

Providing accessible GU services in rural areas is difficult. One solution is to provide a sexual health service in General Practice (GP), close to patients' homes. This may increase access, in particular to those who might not otherwise get tested and avoid the perceived stigma of attending a GUM clinic. A GUM service was set up in 2008 within a General Practice setting (syndromic management only), in an area of high need (HIV prevalence 2.58 per 1000 PHE 2015).We aim to describe the outcomes of running a GU clinic within General Practice.

\section{Background}

A GUM service was set up using the premises of a local GP who was employed by the GUM trust. The nearest hub clinic was 7 miles away.

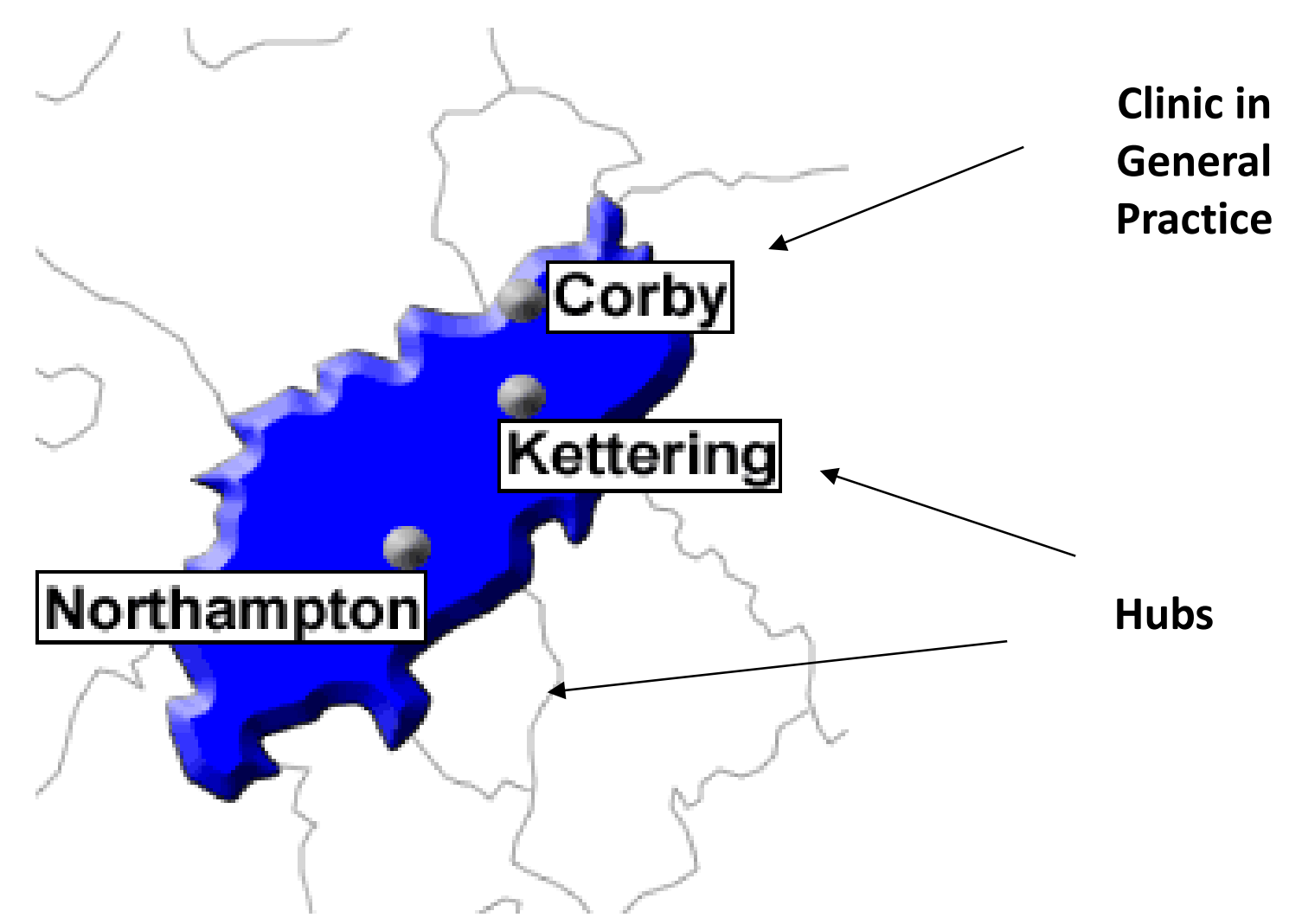

The clinic was run with a doctor (GP), a band 6 nurse and an HCA. No microscopy was available on site but cases were treated syndromically and in cases of suspected NSU, slides were taken for reading back at the hub the following day. Injectable medication was able to be delivered on site, including hepatitis $B$ vaccination and gonorrhoea treatment, but cases for PEPSE were referred to the hub clinics. Booking was by appointment only.

\section{Methods}

Demographics, attendance and diagnosis data was collected and analysed from 2008-2016. All patients were included and compared to patients attending the county hub clinics.

\section{Results}

A total of 1081 patients were seen (1826 attendances) with a median of 200 (186-221) attendances per year.

604 diagnoses of any infection were made (33.1\%). The distribution of GUMCAD diagnoses made is shown in table 1.

\begin{tabular}{|c|c|c|c|c|}
\hline Diagnosis & $\mathbf{n = 6 0 4}$ & $\begin{array}{c}\text { \% all } \\
\text { diagnoses }\end{array}$ & $\begin{array}{c}\text { \% all } \\
\text { patients }\end{array}$ & $\begin{array}{c}\text { \% } \\
\text { attendances }\end{array}$ \\
\hline Chlamydia & 190 & 31.4 & $\mathbf{1 7 . 5}$ & 10.4 \\
\hline Gonorrhoea & 7 & 1.2 & 0.6 & 0.4 \\
\hline Syphilis & 1 & 0.2 & 0.09 & 0.05 \\
\hline HIV & 1 & 0.2 & 0.09 & 0.05 \\
\hline NSU & 36 & 6.0 & 3.3 & 2.0 \\
\hline Genital HPV & 232 & 38.4 & $\mathbf{2 1 . 5}$ & 12.7 \\
\hline HSV & 18 & 3.0 & 1.7 & 1.0 \\
\hline TV & 0 & 0.0 & 0.0 & 0.0 \\
\hline $\begin{array}{c}\text { BV/anaerobic } \\
\text { infection }\end{array}$ & 70 & 11.5 & 6.5 & 3.8 \\
\hline Candida & 49 & 8.1 & 4.5 & 2.7 \\
\hline
\end{tabular}

Genital warts was the most commonly seen infection in $21.5 \%$ of all patients seen. $17.5 \%$ of all patients attending had Chlamydia compared to a yearly average diagnosis of $12.5 \%$ for the nearest hub. One HIV infection was diagnosed.

61 (3.3\% of all attendances) were treated as contacts of Chlamydia, and $3(0.16 \%)$ as a contact of Gonorrhoea. 922(85\%) lived in the town where the clinic was held. $53.8 \%$ (582) had never been seen in GU in our county before compared to $32.6 \%$ in the hub clinics. 440 (41\%) were men, of which 40 (9\%) were MSM.

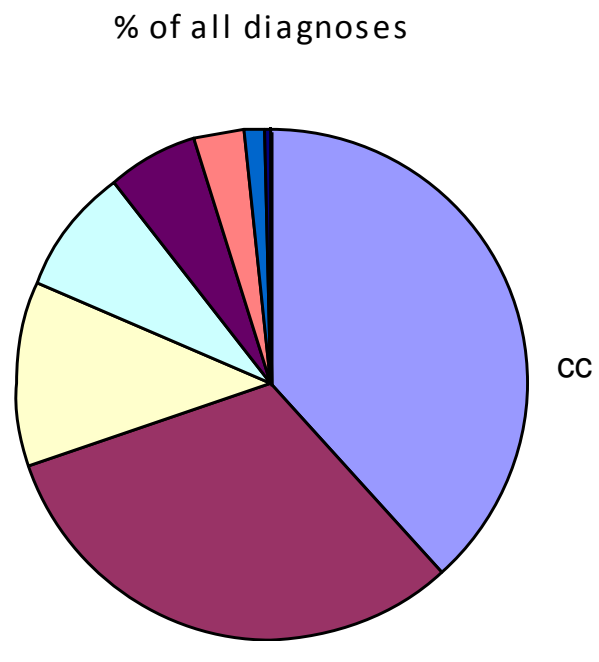

\section{Discussion}

- In rural areas where transport links are limited, a GU clinic run in GP offers an efficient, anonymous service

- Services can be offered in this setting with few extra resources providing an alternative point of access for patients. 